\title{
Influência do Tempo na Desinfecção de Alginato Contaminado com Staphylococcus Aureus em Ácido Peracético ou Gluataraldeído
} Influence of the Time for the Disinfection of Alginate Infected with Staphylococcus Aureus in Glutaraldehyde and Peracetic Acid

\section{Daniela Martins Meira ${ }^{1}$, Themis Collares ${ }^{2}$, Sueli Teresinha Vand Der Sand ${ }^{3}$, Fabrício Mezzomo Collares ${ }^{4}$, Vicente Castelo Branco} Leitune $^{5}$, Susana Maria Werner Samuel ${ }^{6}$

\begin{abstract}
Objective: The aim of this study was to evaluate the effectiveness of peracetic acid and glutaraldehyde for the disinfection of alginate contaminated with Staphylococcus aureus as a function of immersion time (10 and $05 \mathrm{~min}$ ).

Materials and methods: The specimens were previously contaminated with $\mathrm{S}$. aureus and then divided into six groups based on the disinfectant substance and immersion time. The samples were incubated in $20 \mathrm{ml}$ of sterile $\mathrm{BHI}$ broth in an oven at $35 \pm 2{ }^{\circ} \mathrm{C}$ and shakd at $100 \mathrm{rpm}$ for 16 hours. Subsequently the samples of the broth from all the test tubes were plated to determine the presence or absence of viable cells.

Results: The results showed that the control groups and that just washed in sterile water showed bacterial growth.

Conclusion: The peracetic acid and glutaraldehyde was also effective for disinfection of alginate infected with $\mathrm{S}$. aureus, both by immersion time of 10 and 5 minutes
\end{abstract}

Keywords: peracetic acid, disinfection, impression materials, alginate, glutaraldehyde

\section{Resumo}

Objetivo: O objetivo deste estudo foi avaliar a eficácia do ácido peracético e do glutaraldeído na desinfecção do alginato contaminado com Staphylococcus aureus em função do tempo de imersão (10 e 5 $\min )$.

Materiais e métodos: Os corpos de prova foram previamente contaminados com $S$. aureus e em seguida divididos em seis grupos de acordo com a substância desinfetante e o tempo de imersão. As amostras foram incubadas em $20 \mathrm{~mL}$ de caldo BHI estéril em estufa a $35 \pm 2{ }^{\circ} \mathrm{C}$, sob agitação de $100 \mathrm{rpm}$, por 16 horas. Posteriormente as amostras do caldo de todos os tubos de ensaio foram semeadas para determinar a presença ou ausência de células viáveis.

Resultados: Os resultados mostraram que os grupos controle e o lavado em água estéril apresentaram crescimento bacteriano. Conclusão: $O$ ácido peracético foi igualmente eficaz ao glutaraldeído para desinfecção, do alginato contaminado com $S$. aureus, por imersão tanto no tempo de 10 quanto 5 minutos

Palavras-chave: ácido peracético, desinfecção, materiais de moldagem, alginato, glutaraldeído
${ }^{1}$ Aluna do Programa de Pós-Graduação em Odontologia, Universidade Federal do Rio Grande do Sul, Porto Alegre, Rio Grande do Sul, Brasil.

${ }^{2}$ Aluna de Graduação, Instituto de Ciências Básicas da Saúde, Universidade Federal do Rio Grande do Sul, Porto Alegre, Rio Grande do Sul, Brasil.

${ }^{3}$ Professora Associada II do Instituto de Ciências Básicas da Saúde, Universidade Federal do Rio Grande do Sul, Porto Alegre, Rio Grande do Sul, Brasil.

${ }^{4}$ Professor Adjunto do Departamento de Odontologia Conservadora, Universidade Federal do Rio Grande do Sul, Porto Alegre, Rio Grande do Sul, Brasil.

${ }^{5}$ Aluno de Doutorado, Laboratório de Materiais Dentários, Universidade Federal do Rio Grande do Sul, Porto Alegre, Rio Grande do Sul, Brasil.

${ }^{6}$ Professora Titular do Departamento de Odontologia Conservadora, Universidade Federal do Rio Grande do Sul, Porto Alegre, Rio Grande do Sul, Brasil.

Correspondência: Susana Maria Werner Samuel

Endereço: Faculdade de Odontologia, Universidade Federal do Rio Grande do Sul Rua Ramiro Barcelos, $2492-4^{\circ}$ andar - Laboratório de Materiais Dentários, CEP 90035-003, Porto Alegre - RS, Brasil

Fone: (51) 33085197

Data de Submissão: 10/04/2012

Data de Aceite: 17/05/2012

\section{Introdução}

O alginato ou hidrocolóide irreversível é um material comumente utilizado para a tomada de impressões rotineiras de pacientes. Durante a tomada de impressão, o alginato entra em íntimo contato com a microbiota oral do paciente e, após sua geleificação, carrega consigo saliva, microrganismos e, eventualmente, sangue na sua superfície e no seu interior (MCNEILL et al., 1992; AL-JABRAH et al., 2007; EGUSA et al., 2008). Para o exercício adequado da Odontologia, é necessária a aplicação de rígidos protocolos de biossegurança a fim de proteger o paciente, o profissional e toda a equipe de trabalho. O cirurgião-dentista, desta forma, assume total responsabilidade pela biossegurança, devendo estar ciente sobre as maneiras de esterilização e desinfecção de seus materiais a fim de evitar o risco de contaminação-cruzada.

O processo de desinfecção de impressões de alginato deve ser rápido, pois o material deve ser vazado tão logo seja removido da boca, a fim de prevenir alterações dimensionais devido aos fenômenos de sinérese e embebição (SHEN, 2005). Atualmente, os agentes desinfetantes mais descritos na literatura para a desinfecção de moldagens de alginato são o glutaraldeído (2\%) e o hipoclorito de sódio (1\%). Entretanto ambas soluções desinfetantes apresentam problemas, como a elevada toxicidade, alteração dimensional (TAYLOR et al., 2002; AHMAD et al., 2007) e a incompatibilidade com as moldeiras utilizadas (AHMAD et al., 2007). O ácido peracético tem sido muito utilizado em hospitais para a desinfecção de artigos por 
ser atóxico e biodegradável, contudo sua eficácia como desinfetante de hidrocolóides irreversíveis ainda não foi avaliada.

$\mathrm{Na}$ literatura, existem poucos estudos que avaliam a eficácia desses desinfetantes. A maioria dos trabalhos relaciona a desinfecção com alterações dimensionais do próprio alginato e do futuro modelo de gesso, sem mesmo saber se houve a efetiva desinfecção. Além disto, deve haver uma preocupação constante em se tentar estabelecer um protocolo universal para a desinfecção de impressões que seja de fato efetivo, o que de fato, ainda não existe (KOTSIOMITI et al., 2008).

Assim, o presente estudo tem como objetivo avaliar a eficácia do ácido peracético em desinfetar o alginato contaminado com $S$. aureus em dois diferentes tempos de imersão.

\section{Materiais e Métodos}

Os materiais utilizados como desinfetantes e suas respectivas marcas comerciais estão descritos na Tabela 1.

Tabela 1. Soluções desinfetantes e suas respectivas marcas comerciais.

\begin{tabular}{lll} 
Solução Desinfetante & Marca Comercial & Origem \\
\hline Glutaraldeído 2\% & Glutaron II & Rioquímica - Brasil \\
Ácido Peracético 0.2\% & Sterilife & Lifemed - Brasil \\
\hline
\end{tabular}

Um pesquisador treinado realizou todos os processos do experimento. Cada desinfetante (glutaraldeído ou ácido peracético) foi utilizado para desinfecção do corpos de prova de alginato, por 5 ou 10 minutos, previamente contaminados por $S$. aureus.

\section{Confecção dos corpos de prova}

Para avaliar cada desinfetante foram confeccionados corpos de prova de alginato tipo II geleificado (Jeltrate, Dentsply, Brasil). Foi utilizada uma matriz plástica com dimensões de $10 \times 8,5 \mathrm{~cm}$ e $4 \mathrm{~mm}$ de espessura contendo casulos com $1,5 \mathrm{~cm}$ de diâmetro cada, para a confecção dos corpos de prova. Com uma espátula plástica e um gral de borracha desinfetados com solução de álcool $70 \%$, duas medidas do pó de alginato foram espatuladas com duas medidas de água, conforme as instruções do fabricante. Todo o alginato foi dispensado sobre a matriz e, sobre o conjunto, uma laje de vidro estéril e uma carga de $1 \mathrm{Kg}$ sobre a laje. Transcorrido o tempo de geleificação de 2 min, a carga e a laje foram retiradas e os corpos de prova de alginato foram removidos da matriz. Com o auxílio de um paquímetro digital foram obtidas as dimensões dos corpos de prova $(1,5( \pm 0,2) \mathrm{cm}$ de diâmetro e $4( \pm 0,2) \mathrm{mm}$ de espessura) e foram utilizados no estudo quando não apresentavam qualquer defeito visível como bolhas e rasgamento. Os corpos de prova aprovados foram armazenados em uma placa de Petri estéril.

\section{Confecção do caldo de cultura e contaminação dos corpos de} prova

Um Erlenmeyer contendo $60 \mathrm{~mL}$ de caldo Brain Heart Infusion $(\mathrm{BHI})$ foi inoculado com $10 \%(\mathrm{v} / \mathrm{v})$ de uma cultura de Staphylococcus aureus previamente crescida por $16 \mathrm{~h}$ a $35^{\circ} \mathrm{C} \pm 2$. A cultura foi incubada sob agitação de $120 \mathrm{rpm}$ a $35^{\circ} \mathrm{C} \pm 2$ por um período de 6 $( \pm 1)$ horas, até que atingisse a concentração de células 0,5 na escala MacFarlan. Após o crescimento, $30 \mathrm{~mL}$ do caldo foram vertidos em uma placa de Petri estéril. Cada um dos corpos de prova foi removido e transferido para a Placa que continha o meio de cultura. Cada corpo de prova permaneceu individualmente submerso no meio de cultura contendo $S$. aureus durante $3 \mathrm{~min}$.

\section{Tratamento dos corpos de prova contaminados}

Após a etapa de contaminação, cada um dos corpos de prova passou por um tipo de tratamento conforme a solução e o tempo de imersão (Tabela 2). Para a desinfecção dos corpos de prova contaminados foram utilizados $100 \mathrm{~mL}$ de cada desinfetante. Para cada desinfetante, um frasco era utilizado para a desinfecção para o tempo de $5 \mathrm{~min}$; e outro, para o tempo de $10 \mathrm{~min}$.

Os corpos de prova foram inicialmente lavados com $50 \mathrm{~mL}$ de água destilada estéril contida a uma vazão de $2,5 \mathrm{ml} / \mathrm{s}$. Uma segunda lavagem foi realizada após a imersão na solução (glutaraldeído ou ácido peracético).

Tabela 2. Descrição dos grupos do estudo, conforme as etapas de contaminação, lavagem inicial (lav. incial), imersão em solução desinfetante por 5 ou 10 minutos e lavagem final (lav.final).

\begin{tabular}{|c|c|c|c|c|c|}
\hline \multirow[b]{2}{*}{ Grupos } & \multirow[b]{2}{*}{ Contaminação } & \multirow{2}{*}{$\begin{array}{l}\text { Lav. } \\
\text { Inicial }\end{array}$} & \multicolumn{2}{|l|}{ Imersão } & \multirow{2}{*}{$\begin{array}{l}\text { Lav. } \\
\text { Final }\end{array}$} \\
\hline & & & $5 \mathrm{~min}$ & $10 \mathrm{~min}$ & \\
\hline $\mathbf{G}_{\text {cont }}$ & $\sqrt{ }$ & - & - & - & - \\
\hline $\mathbf{G}_{\text {lav }}$ & $\sqrt{ }$ & $\sqrt{ }$ & - & - & - \\
\hline $\mathbf{G}_{\text {gluta5 }}$ & $\sqrt{ }$ & $\sqrt{ }$ & Glutaraldeído & - & $\sqrt{ }$ \\
\hline $\mathbf{G}_{\text {gluta10 }}$ & $\sqrt{ }$ & $\sqrt{ }$ & - & Glutaraldeído & $\sqrt{ }$ \\
\hline $\mathbf{G}_{\text {acper5 }}$ & $\sqrt{ }$ & $\sqrt{ }$ & $\begin{array}{l}\text { Ácido } \\
\text { Peracético }\end{array}$ & - & $\sqrt{ }$ \\
\hline $\mathbf{G}_{\text {acper10 }}$ & $\sqrt{ }$ & $\sqrt{ }$ & - & $\begin{array}{l}\text { Ácido } \\
\text { Peracético }\end{array}$ & $\sqrt{ }$ \\
\hline
\end{tabular}

\section{Incubação dos corpos de prova após o tratamento de desinfecção}

Após o tratamento os corpos de prova foram imersos em um tubo de ensaio com a identificação do grupo contendo $20 \mathrm{~mL}$ de caldo $\mathrm{BH}$ estéril. Os tubos de ensaio foram incubados em estufa a $35^{\circ} \mathrm{C} \pm$ 2, sob agitação de 100 rpm, por 16 horas.

\section{Análise da presença do número de bactérias viáveis em cada grupo}

Todas as amostras foram semeadas para determinar a presença ou ausência de células viáveis. Em placas de Petri contendo agar padrão para contagem (PCA) (Acumedia-MichiganUSA) foram semeados $0,1 \mathrm{~mL}$ da cultura de cada tubo de ensaio, após homogenização sob agitação em Vortex durante 10s. Todas as amostras foram inoculadas em duplicata pelo do método de espalhamento em superfície, com o auxílio de uma alça de Drigalski. As placas foram incubadas a $35 \stackrel{\circ}{\circ} \pm 2$, por $24 \mathrm{~h}$. Após o período de incubação foi verificado se houve crescimento bacteriano. No caso de crecimento, o número de Unidades Formadoras de Colônia por $\mathrm{mL}$ (UFC/mL) de cada amostra foi determinado.

\section{Resultados}

Os resultados são apresentados na Tabela 3. O $\mathrm{G}_{\text {cont }}$ (grupo apenas contaminado e incubado) apresenta mais de 300 unidade formadoras de colônia por mililitro, indicando a contaminação do corpo de prova de alginato. $\mathrm{O} \mathrm{G}_{\mathrm{lav}}$, apenas lavado com água estéril após a contaminação, também apresentou crescimento bacteriano. 
Os demais grupos, com todos os regimes de desinfecção propostos, foram eficazes para evitar a presença e o crescimento bacteriano.

Tabela 3. Resultados em UFC/mL dos grupos.

\begin{tabular}{ll}
\hline Grupos & UFC/mL \\
\hline Gcont & $>300$ \\
Glav & $>300$ \\
Ggluta5 & 0 \\
Ggluta10 & 0 \\
Gacper5 & 0 \\
Gacper10 & 0 \\
\hline
\end{tabular}

\section{Discussão}

Na literatura já é consenso que não há um protocolo universal para a realização de desinfecção de impressões (KOTSIOMITI et al., 2008). Muitos estudos se preocupam com a alteração dimensional que a solução desinfetante pode acarretar no material de impressão (JONES et al., 1988; HUTCHINGS et al., 1996; JOHNSON et al., 1998), sem mesmo saber se esta foi eficaz em eliminar a população microbiana.

O glutaraldeído é uma das soluções desinfetantes de impressões mais evidenciada em trabalhos científicos quando o assunto é desinfecção de impressões e, mais especificamente, de alginato. A principal vantagem desta solução é não alterar as propriedades do alginato, garantindo um modelo de gesso fidedigno para estudo e trabalho (JONES et al., 1990; JOHNSON et al., 1998; BOCK et al., 2008). Além disso, o glutaraldeído é eficaz contra a microbiota bucal em estudos clínicos (AL-JABRAH et al., 2007), bem como contra microrganismos patogênicos em estudos in vitro (KAPLAN et al., 1994), tais como, Pseudomonas aeruginosa (JENNINGS et al., 1991), Candida albicans (JENNINGS et al., 1991), Streptococcus sanguis (MCNEILL et al., 1992). Outro fator importante é que a solução de glutaraldeído $2 \%$ não é corrosiva, sendo viável para desinfecção de impressões tomadas com moldeiras metálicas, sem danificá-las ao longo do seu uso. Entretanto o glutaraldeído é tóxico para a equipe de saúde envolvida em seu uso (TAKIGAWA et al., 2006).

A aplicação solução de hipoclorito de sódio ainda é discutida na literatura apesar de alguns dados serem contraditórios sobre sua eficácia e alteração dimensional no alginato (AHMAD et al., 2007) e (22). Um estudo avaliou a eficácia da solução de hipoclorito de sódio para a desinfecção de consecutivas impressões de alginato e algumas desvantagens ficaram evidentes. Primeiramente, o próprio alginato por conter sódio, potássio e cálcio, como qualquer outro composto orgânico, reage rapidamente com os compostos clorados, diminuindo sua disponibilidade no desinfetante, diminuindo sua capacidade bactericida. Além disto, as moldeiras metálicas mostraram sinais de corrosão após os 10 min de sua imersão na solução de hipoclorito e essa liberação de íons também diminui a disponibilidade de compostos clorados na superfície do alginato, podendo acarretar falhas na presa do gesso a ser vazado (22). Outro fator, não menos importante é a diluição causada pela lavagem prédesinfecção, o que também leva à perda de compostos clorados (GERHARDT et al., 1991). Em um estudo o hipoclorito de sódio $(0.525 \%)$ foi eficaz em eliminar Pseudomonas aeruginosa, Staphylococcus aureus, e Salmonella choleraesuis. Entretanto, não foi eficaz em eliminar Mycobacterium bovis e Bacillus subtilis (SCHWARTZ et al., 1994). Já em outro estudo a solução de hipoclorito de sódio $1 \%$ foi eficaz em eliminar $S$. aureus, mas 0 processo causou falhas na superfície do gesso, dificultando a reprodução de detalhes (TAYLOR et al., 2002).

O ácido perácetico é um desinfetante biodegradável, pois decompõem- se em ácido acético, água e oxigênio, sendo nãoalergeno e não deletério ao meio ambiente. Assim, seu uso vem sendo difundido principalmente em ambientes hospitalares. Um estudo in situ mostrou que o ácido peracético foi eficaz em eliminar os microrganismos Pseudomonas aeruginosa, esporos de Clostridium difficile, que é resistente ao glutaraldeído, Mycobacterium chelonae, Enterococcus faecalis e Staphylococcus aureus Resitente à Meticilina (MRSA) contidos em endoscópios (SATTAR et al., 2006). Na Odontologia, poucos estudos pesquisam o ácido peracético como desinfetante. A solução de ácido peracético $0,2 \%$ se mostrou eficaz em desinfetar sob imersão de 5 min resinas acrílicas contaminadas com saliva humana, Bacillus subtilis e Bacillus stearothermophilus (CHASSOT et al., 2006). Um estudo avaliou a eficácia de soluções de ácido peracético em diluições de 800, 1500 e 2500 ppm, utilizando, dentre outros microrganismos, $S$. aureus e avaliou o efeito corrosivo da solução. Concluiu-se que a solução em 2500 ppm é eficaz e apresenta um mínimo efeito corrosivo (CERETTA et al., 2008). Entretanto ainda não há estudos correlacionando a solução de ácido peracético como desinfetante para alginato.

A contaminação foi realizada em total submersão durante 03 minutos em um caldo de $S$. aureus padronizado em uma concentração de celúlas 0,5 na escala Mac Farlan proporcionou um alto desafio microbiano para a desinfecção, além de simular o contagio clínico no ato da tomada de uma impressão que é realizada durante o tempo de 02 a 03 minutos. Um estudo in vitro também contaminou as amostras por submersão durante 03 minutos em caldos de Candida albicans e Pseudomona aeruginosa e comprovou que o alginato retém mais microrganismos que o polivinilsiloxano (JENNINGS et al., 1991).

Logo após a contaminação, o corpo de prova sofria uma lavagem inicial para remoção de excesso de carga bacteriana da superfície, assim como na prática clínica, com $50 \mathrm{ml}$ da água destilada estéril em uma vazão de aproximadamente $2 \mathrm{ml} / \mathrm{s}$. Entretanto apenas a realização da lavagem $\left(G_{\text {lav }}\right)$ não foi eficaz para reduzir o nível de contaminação dos corpos de prova do grupo que apenas sofreu contaminação $\left(\mathrm{G}_{\text {cont }}\right)$, ou seja, mais de $300 \mathrm{UFC} / \mathrm{mL}$. Estes dados retomam a importância da realização de um correto protocolo de desinfecção de impressões e que a lavagem por si só é insuficiente para eliminar microrganismos, o que contradiz os dados de um estudo que relata que a lavagem poderia remover $90 \%$ dos microrganismos (MCNEILL et al., 1992). Estes dados vão de encontro, principalmente, com características estruturais de porosidade do alginato, fazendo com que realmente retenha mais microorganismos em seu interior e, desta forma, a lavagem agiria apenas superficialmente. Assim, são preocupantes dados que referem, por exemplo, que apenas $54 \%$ das impressões são desinfetadas conforme um protocolo no Japão (EGUSA et al., 2008), ou seja, $46 \%$ dessas impressões e seus respectivos modelos seguem contaminados para o laboratório de prótese.

O desinfetante eleito deve ser eficaz em eliminar microrganismos patogênicos presentes no alginato após a impressão do paciente. Dentre as espécies encontradas na microbiota bucal, o Staphylococcus aureus, uma bactéria Gram-positiva, é reconhecida como uma bactéria de grande importância em infecções em seres humanos. Este microrganismo tem como nicho ecológico a parte anterior das fossas nasais e está presente em $30 \%$ da população. $O$ $S$. aureus está associado com diversas patologias, como osteomielite, infecções pulmonares e infecções do Sistema Nervoso Central (BAMBERGER et al., 2005). Desta forma a prevenção do contágio é uma necessidade, tendo em vista o difícil tratamento para esta infecção (KLUYTMANS et al., 1997). Neste contexto, a desinfecção 
de impressões deve ser eficaz para todas as espécies, inclusive para as mais virulentas como o $S$. aureus.

Após a desinfecção, todos os corpos de prova foram novamente lavados com $50 \mathrm{~mL}$ água destilada estéril com o intuito de remover resíduos do desinfetante que pudessem permanecer no corpo de prova, assim como na prática clínica, evitando que resíduos do desinfetante permaneçam na superfície e ocasionem falhas no modelo de gesso (OWEN et al., 1993; BODEN et al., 2001).

O presente estudo confirma a eficácia do glutaraldeído em desinfetar o alginato, contaminado com S.aureus, tanto por 10 min de imersão que já é referência na literatura (JONES et al., 1988; JONES et al., 1990; JENNINGS et al., 1991; JOHNSON et al., 1998; BOCK et al., 2008), como também em um tempo inferior, ou seja, por 5 min. $O$ ácido peracético, desinfetante promissor, por ser biodegradável, atóxico e já difundido em meio hospitalar, também se mostrou efivaz tanto para a desinfecção do alginato, tanto em imersões por 10 minutos quanto por 5 minutos. Desta forma, obtemos o mesmo desempenho para ambas as soluções desinfetantes, ou seja, ambas foram eficazes em eliminar S.aureus dos corpos de prova de alginato tanto em um regime de imersão de 10 min quanto de 5 min.

\section{Referências}

AHMAD, S., TREDWIN, C. J., NESBIT, M., et al. Effect of immersion disinfection with Perform-ID on alginate, an alginate alternative, an addition-cured silicone and resultant type III gypsum casts. Br Dent $\mathbf{J}$, v.202, n.1, Jan 13, p.E1; discussion 36-7. 2007.

AL-JABRAH, O., AL-SHUMAILAN, Y. e AL-RASHDAN, M. Antimicrobial effect of 4 disinfectants on alginate, polyether, and polyvinyl siloxane impression materials. Int J Prosthodont, v.20, n.3, May-Jun, p.299-307. 2007.

BAMBERGER, D. M. e BOYD, S. E. Management of Staphylococcus aureus infections. Am Fam Physician, v.72, n.12, Dec 15, p.2474-81. 2005.

BOCK, J. J., FUHRMANN, R. A. e SETZ, J. The influence of different disinfectants on primary impression materials. Quintessence Int, v.39, n.3, Mar, p.e93-8. 2008.

BODEN, J., LIKEMAN, P. e CLARK, R. Some effects of disinfecting solutions on the properties of alginate impression material and dental stone. Eur J Prosthodont Restor Dent, v.9, n.3-4, Sep-Dec, p.131-5. 2001.

CERETTA, R., PAULA, M. M., ANGIOlETTO, E., et al. Evaluation of the effectiveness of peracetic acid in the sterilization of dental equipment. Indian J Med Microbiol, v.26, n.2, Apr-Jun, p.117-22. 2008.

CHASSOT, A. L., POISL, M. I. e SAMUEL, S. M. In vivo and in vitro evaluation of the efficacy of a peracetic acid-based disinfectant for decontamination of acrylic resins. Braz Dent J, v.17, n.2, p.117-21. 2006.

EGUSA, H., WATAMOTO, T., ABE, K., et al. An analysis of the persistent presence of opportunistic pathogens on patient-derived dental impressions and gypsum casts. Int J Prosthodont, v.21, n.1, Jan-Feb, p.62-8. 2008

GERHARDT, D. E. e WILLIAMS, H. N. Factors affecting the stability of sodium hypochlorite solutions used to disinfect dental impressions. Quintessence Int, v.22, n.7, Jul, p.587-91. 1991.
HUTCHINGS, M. L., VANDEWALLE, K. S., SCHWARTZ, R. S., et al. Immersion disinfection of irreversible hydrocolloid impressions in $\mathrm{pH}$ adjusted sodium hypochlorite. Part 2: Effect on gypsum casts. Int $\mathbf{J}$ Prosthodont, v.9, n.3, May-Jun, p.223-9. 1996.

JENNINGS, K. J. e SAMARANAYAKE, L. P. The persistence of microorganisms on impression materials following disinfection. Int $\mathbf{J}$ Prosthodont, v.4, n.4, Jul-Aug, p.382-7. 1991.

JOHNSON, G. H., CHELLIS, K. D., GORDON, G. E., et al. Dimensional stability and detail reproduction of irreversible hydrocolloid and elastomeric impressions disinfected by immersion. $\mathbf{J}$ Prosthet Dent, v.79, n.4, Apr, p.446-53. 1998.

JONES, M. L., NEWCOMBE, R. G., BARRY, G., et al. A Reflex Plotter investigation into the dimensional stability of alginate impressions following disinfection by varying regimes employing 2.2 per cent glutaraldehyde. Br J Orthod, v.15, n.3, Aug, p.185-92. 1988.

JONES, M. L., NEWCOMBE, R. G., BELLIS, H., et al. The dimensional stability of self-disinfecting alginate impressions compared to various immersion regimes. Angle Orthod, v.60, n.2, Summer, p.123-8. 1990.

KAPLAN, B. A., GOLDSTEIN, G. R. e BOYLAN, R. Effectiveness of a professional formula disinfectant for irreversible hydrocolloid. $\mathbf{J}$ Prosthet Dent, v.71, n.6, Jun, p.603-6. 1994.

KLUYTMANS, J., VAN BELKUM, A. e VERBRUGH, H. Nasal carriage of Staphylococcus aureus: epidemiology, underlying mechanisms, and associated risks. Clin Microbiol Rev, v.10, n.3, Jul, p.505-20. 1997.

KOTSIOMITI, E., TZIALLA, A. e HATJIVASILIOU, K. Accuracy and stability of impression materials subjected to chemical disinfection - a literature review. J Oral Rehabil, v.35, n.4, Apr, p.291-9. 2008.

MCNEILL, M. R., COULTER, W. A. e HUSSEY, D. L. Disinfection of irreversible hydrocolloid impressions: a comparative study. Int $\mathbf{J}$ Prosthodont, v.5, n.6, Nov-Dec, p.563-7. 1992.

OWEN, C. P. e GOOLAM, R. Disinfection of impression materials to prevent viral cross contamination: a review and a protocol. Int $\mathbf{J}$ Prosthodont, v.6, n.5, Sep-Oct, p.480-94. 1993.

SATTAR, S. A., KIBBEE, R. J., TETRO, J. A., et al. Experimental evaluation of an automated endoscope reprocessor with in situ generation of peracetic acid for disinfection of semicritical devices. Infect Control Hosp Epidemiol, v.27, n.11, Nov, p.1193-9. 2006.

SCHWARTZ, R. S., BRADLEY, D. V., JR., HILTON, T. J., et al. Immersion disinfection of irreversible hydrocolloid impressions. Part 1: Microbiology. Int J Prosthodont, v.7, n.5, Sep-Oct, p.418-23. 1994.

SHEN, C. In: K. Anusavice (Ed.). Philip's Science of Dental Materials, 2005

TAKIGAWA, T. e ENDO, Y. Effects of glutaraldehyde exposure on human health. J Occup Health, v.48, n.2, Mar, p.75-87. 2006.

TAYLOR, R. L., WRIGHT, P. S. e MARYAN, C. Disinfection procedures: their effect on the dimensional accuracy and surface quality of irreversible hydrocolloid impression materials and gypsum casts. Dent Mater, v.18, n.2, Mar, p.103-10. 2002. 